\title{
Long-term follow-up in patients with gastric antral vascular ectasia (GAVE) after treatment with endoscopic band ligation (EBL)
}

\section{(2)(1) $\odot \odot$}

\author{
Authors \\ John Eccles, Vanessa Falk, Aldo J. Montano-Loza, Sergio Zepeda-Gómez
}

Institution

Division of Gastroenterology, University of Alberta Hospital, Edmonton, Alberta, Canada

submitted 10.3.2019

accepted after revision 12.6 .2019

\section{Bibliography}

DOI https://doi.org/10.1055/a-0977-2870 |

Endoscopy International Open 2019; 07: E1624-E1629

(c) Georg Thieme Verlag KG Stuttgart · New York eISSN 2196-9736

Corresponding author

Sergio Zepeda-Gómez, MD, Associate Professor, Division of Gastroenterology, University of Alberta, Edmonton, Canada Fax: +7804921455

zepedago@ualberta.ca

\section{ABSTRACT}

Background and study aims Gastric antral vascular ectasia (GAVE) is a capillary-type vascular malformation of the gastric antrum, usually diagnosed endoscopically in patients presenting with iron deficiency anemia or gastrointestinal bleeding. While there is established evidence for treatment with thermal modalities, such as argon plasma coagulation (APC) therapy, more recent studies have shown endoscopic band ligation (EBL) to be safe and effective in achieving remission. Our study aimed to evaluate longterm outcomes of patients with GAVE who underwent EBL at our institution.

Patients and methods We retrospectively reviewed data from 33 patients with GAVE who underwent esophagogastroduodenoscopy and EBL between September 2012 and July 2017 within our institution, looking primarily at clinical response, recurrence, and blood transfusion requirements. Results Clinical response was achieved in 27 patients (81.8\%). Among responders, recurrence-free survival decreased with time from $88 \%$ at 1 year to $44 \%$ at 2 years. Thirteen patients $(48.1 \%$ ) had recurrence of GAVE at a mean time of 18.2 months (range $4.7-51.8$ ). The only predictor of recurrence was greater number of pre-procedure blood transfusions.

Conclusion This is the first study to evaluate long-term response and recurrence in patients with GAVE after treatment with EBL and predictors of clinical response after initial endoscopic therapy have been identified. While we were able to demonstrate excellent remission achievement rates in our GAVE patients who had undergone EBL, close clinical follow-up is clearly required as almost $50 \%$ will have recurrence at around 18 months.

\section{Introduction}

Gastric antral vascular ectasia (GAVE) is a capillary-type vascular malformation affecting mainly the gastric antrum and corresponds to up to $4 \%$ of upper non-variceal bleeding [1]. The diagnosis of GAVE is generally made at endoscopy, which either shows longitudinal streaks converging at the pylorus (stripe type) or multiple erythematous spots (diffuse type) [2]. On histology, GAVE is characterized by dilated mucosal capillaries, often occluded by fibrin thrombi and rarely associated with inflammation [3]. While patients can be asymptomatic, the majority present with iron-deficiency anemia and occasionally GAVE can cause overt gastrointestinal bleeding. This gastric vascular abnormality has been associated with various diseases including hepatic cirrhosis, renal failure, systemic lupus erythematous, scleroderma, and post-bone marrow transplant [4].

While multiple endoscopic therapies have been proposed for treating GAVE, the most commonly used is argon plasma coagulation (APC) [4]. APC is generally safe; however, it is associated with high recurrence rates [5-7]. More recently, endoscopic band ligation (EBL) has been described as an alternative endoscopic therapy for GAVE. Sinha first described this in a case report in 2006 [8]. Multiple retrospective studies have shown EBL to have lower complication rates and more effectiveness when compared to APC [9-11]. We previously presented results of our experience with EBL for treatment of GAVE in a prospective trial, showing EBL to be safe and effective [9]. The aim of this 
study was to evaluate long-term outcomes in patients with GAVE who underwent EBL at our institution.

\section{Patients and methods}

\section{Study population}

We retrospectively reviewed all data from patients who underwent esophagogastroduodenoscopy between September 2012 and July 2017 in whom GAVE-associated iron deficiency anemia was diagnosed, with or without associated overt bleeding. Patients had to be 18 years or older and present with anemia. Patients who were not anemic, had other sources of gastrointestinal blood loss, or had undergone endoscopic treatment of GAVE within the preceding 3 months were excluded from this study (> Fig. 1).

Our initial experience was published in 2015 based on a prospective trial that included 21 patients [8]. Data from these patients were retrospectively analyzed for long-term follow-up and patients with a new diagnosis of GAVE treated with EBL were also included for analysis. Primary endpoints included recurrence of bleeding/anemia and blood transfusion requirements.

Clinical response was defined endoscopically by complete or near-complete eradication of GAVE along with stabilization of hemoglobin levels and/or decrease in blood transfusion requirements. We also documented number of endoscopies (counting any endoscopies related to assessment and/or treatment of GAVE), total number of bands applied, adverse events and need for additional endoscopic therapy with APC.

Experienced endoscopists performed all procedures. Endoscopic appearance of GAVE was classified as either stripe type or diffuse type. Procedural details and post-treatment recommendations including treatment with proton pump inhibitor therapy have been previously described [9].

Following initial EBL, repeat endoscopy was scheduled 6 to 8 weeks later. Subsequent endoscopic examinations and EBL were conducted at the same interval until clinical response was achieved. Hemoglobin, ferritin, and iron levels were tested at 4 weeks and 6 months and annually thereafter.

\section{Statistical analysis}

Data are presented as median with interquartile range, or frequencies and percentages. Normally and non-normally-distributed numeric variables were compared with Student's $t$-test and Mann-Whitney test, respectively. Associations between categorical variables were tested using Fisher's exact test. Survival probabilities were calculated based on the Kaplan-Meier methodology, and the significance of differences between survival curves were calculated by means of the Log Rank (MantelCox) test. Patients lost during follow-up and patients being continuously followed in the clinic were censored at the time of their last visit. Univariate and multivariate analyses were constructed through logistic regression to evaluate features associated with endoscopic response.

In addition, a Cox regression analysis was performed to evaluate factors associated with recurrence among patients who had a response to $E B L$ and the results were reported as hazard

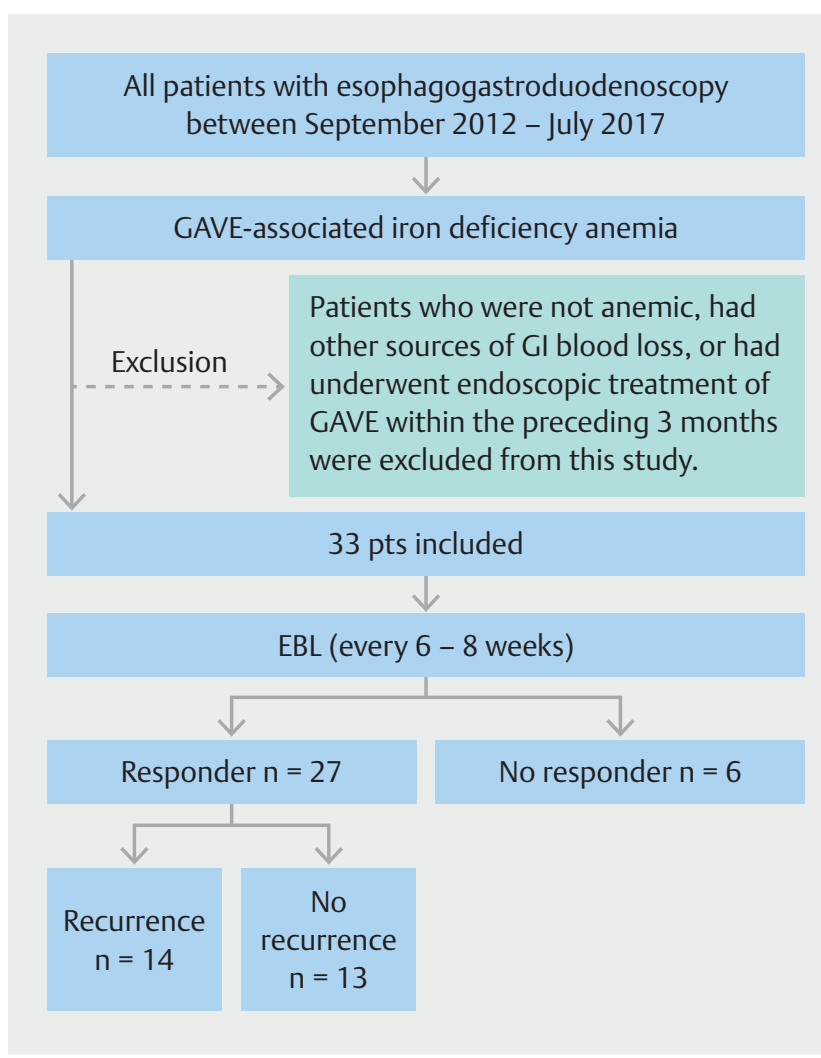

- Fig. 1 Flowchart of patients excluded from/included in the analysis and response to EBL.

ratios (HR) with $95 \%$ confidence intervals $(\mathrm{Cl})$. Variables with a $P<0.10$ in the univariate analysis were included in the multivariate model. All statistical analysis was done in SPSS for Windows (Version 21; IBM, Armonk, New York, United States).

\section{Results}

\section{Patient characteristics}

A total of 33 patients with GAVE were reviewed. Of them, 21 patients had been included in our previous study with longterm follow-up results presented here. Patient demographics and baseline characteristics are presented in $>$ Table 1. Mean overall follow-up length was 35.9 months (range 4.3-76.5 months). Ten patients were followed for more than 48 months, 19 patients for more than 12 months (<48 months), and only four for less than 12 months.

\section{Endoscopic clinical response}

A clinical response was achieved in 27 patients (81.8\%). Mean number of sessions required for eradication of GAVE was 2.9 $[95 \% \mathrm{Cl}=2.2,3.8]$ with the average number of bands to achieve eradication being $12.4[95 \% \mathrm{Cl}=9.9,15.5]$.

When comparing $\mathrm{Hb}$ levels for responders and non-responders, mean pre- and post-EBL Hb levels were significantly lower among patients who did not respond to EBL compared to those who responded $(70 \mathrm{~g} / \mathrm{L}$ vs. $95 \mathrm{~g} / \mathrm{L}, P=0.004$ and $89 \mathrm{~g} / \mathrm{L}$ vs. $111 \mathrm{~g} /$ $\mathrm{L}, P=0.01)$. Mean $\mathrm{Hb}$ level among responders increased signifi- 
- Table 1 Demographic data from GAVE responders vs. non-responders after EBL.

\begin{tabular}{|c|c|c|c|c|}
\hline & $\begin{array}{l}\text { All } \\
(n=33)\end{array}$ & $\begin{array}{l}\text { Responders } \\
(n=27)\end{array}$ & $\begin{array}{l}\text { Non-responders } \\
(n=6)\end{array}$ & $P$ value \\
\hline Gender (females: males) & $24: 9$ & $21: 6$ & $3: 3$ & 0.31 \\
\hline Age (median, IQR) & $67(55-77)$ & $67(55-77)$ & $68(54-84)$ & 0.66 \\
\hline Cirrhosis, n (\%) & $10(30)$ & $9(33)$ & $1(17)$ & 0.64 \\
\hline CRF, n (\%) & $11(33)$ & $8(30)$ & $3(50)$ & 0.38 \\
\hline Other comorbidities, n (\%) & $19(58)$ & $16(59)$ & $3(50)$ & \multirow[t]{9}{*}{0.44} \\
\hline - Diabetes & $7(37)$ & $6(37)$ & $1(33)$ & \\
\hline - Atrial fibrillation & $4(21)$ & $3(19)$ & $1(33)$ & \\
\hline - CAD & $2(11)$ & $2(13)$ & 0 & \\
\hline - Venous thrombosis & $2(11)$ & $2(13)$ & 0 & \\
\hline - Scleroderma & $1(5)$ & $1(6)$ & 0 & \\
\hline - Lymphoma & $1(5)$ & $1(6)$ & 0 & \\
\hline - COPD & $1(5)$ & 0 & $1(33)$ & \\
\hline - Aplastic anemia & $1(5)$ & $1(6)$ & 0 & \\
\hline Anticoagulants/Antiplatelet therapy, n (\%) & $8(24)$ & $7(26)$ & $1(17)$ & 0.18 \\
\hline Mortality, n (\%) & $10(30)$ & $7(26)$ & $3(50)$ & 0.34 \\
\hline Clinical Presentation, n (\%) & 33 & 27 & 6 & 1.00 \\
\hline Iron deficiency anemia & $24(73)$ & $20(74)$ & $4(67)$ & \\
\hline Overt gastrointestinal bleeding & $9(27)$ & $7(26)$ & $2(33)$ & \\
\hline \multicolumn{5}{|l|}{ GAVE type, n (\%) } \\
\hline - Diffuse & $14(42)$ & $12(44)$ & $2(33)$ & \multirow[t]{4}{*}{1.00} \\
\hline - Stripe & $19(58)$ & $15(56)$ & $4(67)$ & \\
\hline - Active bleeding at endoscopy, n (\%) & $13(39)$ & $11(41)$ & $2(33)$ & \\
\hline - Previous treatment with APC, n (\%) & $14(42)$ & $11(41)$ & $3(50)$ & \\
\hline \multicolumn{5}{|l|}{ Hemoglobin level, g/L } \\
\hline - Before EBL & $86(75-100)$ & $95(78-102)$ & $70(49-89)$ & 0.004 \\
\hline - After EBL (final available value) & $105(90-121)$ & $111(94-128)$ & $89(78-99)$ & 0.01 \\
\hline \multicolumn{5}{|l|}{ Ferritin level, $\mu \mathrm{g} / \mathrm{L}$} \\
\hline - Before EBL & $37(14-149)$ & $35(14-119)$ & $162(77-361)$ & 0.07 \\
\hline - After EBL (final available value) ${ }^{1}$ & $40(22-148)$ & $48(24-128)$ & $24(12-181)$ & 0.30 \\
\hline \multicolumn{5}{|l|}{ Iron level, $\mu \mathrm{mol} / \mathrm{L}$} \\
\hline - Before EBL ${ }^{1}$ & $8(5-14)$ & $8(4-14)$ & $7(5-14)$ & 0.80 \\
\hline - After EBL (final available value) & $9(7-16)$ & $9(7-16)$ & $9(5-10)$ & 0.19 \\
\hline \multicolumn{5}{|l|}{ Total number of pRBC units per month, } \\
\hline - Before EBL ${ }^{1}$ & $0.17(0.00-0.58)$ & $0.08(0-0.50)$ & $0.58(0.27-0.71)$ & 0.137 \\
\hline - After EBL ${ }^{1}$ & $0.00(0.00-1.00)$ & $0.00(0.00-0.08)$ & $1.18(0.25-1.78)$ & 0.037 \\
\hline \multicolumn{5}{|c|}{$\begin{array}{l}\text { Categorical and normally-distributed numeric variables were compared with chi squared test and Student's t-test, respectively. Data are presented as median with } \\
\text { 25th-75th percentile range for numeric variables. } \\
\text { GAVE, gastric antral vascular ectasia; EBL, endoscopic band ligation; IQR, interquartile range; CRF, chronic renal failure; CAD, coronary artery disease; APC, argon } \\
\text { plasma coagulation; PRBC, packed red blood cells } \\
{ }^{1} \text { Non-normally distributed variables were compared with the Mann-Whitney test. }\end{array}$} \\
\hline
\end{tabular}


- Table 2 Outcomes in initial responders based upon long-term follow-up.

\begin{tabular}{|c|c|c|c|c|}
\hline & $\begin{array}{l}\text { All Responders } \\
(n=27)\end{array}$ & $\begin{array}{l}\text { Non-recurrence } \\
(n=14)\end{array}$ & $\begin{array}{l}\text { Recurrence } \\
(n=13)\end{array}$ & $P$ value \\
\hline Follow-up & $27(15-51)$ & $21(13-35)$ & $49(31-61)$ & 0.005 \\
\hline Age & $67(55-77)$ & $70(55-81)$ & $67(55-73)$ & 0.53 \\
\hline Gender (females:males) & $21: 6$ & $8: 6$ & 13:0 & 0.02 \\
\hline Cirrhosis, n (\%) & $9(33)$ & $6(43)$ & $3(23)$ & 0.42 \\
\hline CRF, n (\%) & $8(30)$ & $5(36)$ & $3(23)$ & 0.68 \\
\hline Anticoagulants/Antiplatelet therapy, $\mathrm{n}(\%)$ & $7(26)$ & $2(14)$ & $5(38)$ & 0.21 \\
\hline \multicolumn{5}{|l|}{ GAVE type, n (\%) } \\
\hline - Diffuse & $12(44)$ & $7(50)$ & $5(39)$ & 0.70 \\
\hline - Stripe & $15(56)$ & $7(50)$ & $8(62)$ & \\
\hline - Sessions needed for initial eradication ${ }^{1}$ & $3(2-4)$ & $2(1-3)$ & $3(2-5)$ & 0.20 \\
\hline - Bands applied for initial eradication ${ }^{1}$ & $11(8-17)$ & $10(6-15)$ & $11(9-16)$ & 0.55 \\
\hline \multicolumn{5}{|l|}{ Hematological parameters } \\
\hline \multicolumn{5}{|l|}{ Hemoglobin level ( $\mathrm{g} / \mathrm{L})$} \\
\hline - Before EBL & $95(78-102)$ & $85(78-97)$ & $101(79-112)$ & 0.12 \\
\hline - At eradication & $110.5(94-125)$ & $101(88-121)$ & $123(103-134)$ & 0.11 \\
\hline - At recurrence & $97(77-110)$ & $\mathrm{N} / \mathrm{A}$ & $97(77-110)$ & $\mathrm{N} / \mathrm{A}$ \\
\hline - Final available & $111(94-128)$ & $112(100-122)$ & $109(91-133)$ & 0.76 \\
\hline \multicolumn{5}{|l|}{ Total number of pRBC units per month } \\
\hline - Before EBL ${ }^{1}$ & $0.08(0.00-0.50)$ & $0.08(0.06-0.54)$ & $0.08(0.00-0.58)$ & 0.72 \\
\hline - After EBL ${ }^{1}$ & $0.00(0.00-0.08)$ & $0.00(0.00-0.30)$ & $0.00(0.00-60)$ & 0.69 \\
\hline \multicolumn{5}{|c|}{$\begin{array}{l}\text { Categorical and normally-distributed numeric variables were compared with hi squared test and Student's t-test, respectively. Data are presented } \\
\text { 25th-75th percentile range for numeric variables. } \\
\text { CRF, chronic renal failure; GAVE, gastric antral vascular ectasia; EBL, endoscopic band ligation; PRBC, packed red blood cells. } \\
{ }^{1} \text { Non-normally distributed variables were compared with the Mann-Whitney test. }\end{array}$} \\
\hline
\end{tabular}

cantly from pre-EBL to post-EBL $(95 \mathrm{~g} / \mathrm{L}$ vs. $111 \mathrm{~g} / \mathrm{L}, P<0.001)$, whereas non-responders did not achieve a significant rise in Hb level (70 g/L vs., $89 \mathrm{~g} / \mathrm{L}, P=0.156)$ ( $>$ Table 2 ).

\section{Features associated with endoscopic clinical response}

While there was a predictive trend in number of sessions and bands applied in the univariate analysis $(P=0.09$ and $P=0.4$, respectively), the only significant predictor of response to $E B L$ in both univariate and multivariate analysis was pre-procedure hemoglobin level. A higher pre-procedure hemoglobin level was associated with a greater chance of response to EBL ( $\triangleright \mathrm{Ta}$ ble 3).

\section{Endoscopic clinical response and survival}

Since the beginning of the study (September 2012), 12 patients (36.4\%) have died. Causes of death included liver failure (3 patients), renal failure (3 patients), myocardial infarction (2 patients), congestive heart failure (1 patient), pneumonia (1 pa- tient), and unknown (2 patients), but no death secondary to gastrointestinal bleeding.

Mean overall survival was significantly shorter at 20.8 months $[42.5,62.9]$ in patients who did not respond to EBL compared to those who had resolution of GAVE (56.0 [45.6, 66.4], $P=0.03$ ) ( $\triangleright$ Fig. 2). Patients who responded to EBL therapy had a significant lower risk of dying ( $\mathrm{HR} 0.21,95 \% \mathrm{Cl}$ $0.05-0.89, P=0.02)$. Among responders, recurrence-free survival decreased with time from $88 \%$ at 1 year to $44 \%$ at 2 years ( $\triangleright$ Fig.3). Of the six patients who did not achieve a clinical response, one patient went on to have a laparoscopic distal gastrectomy. Three of these patients are deceased, with average time to death from EBL 12.3 months (range 4-18).

\section{Factors associated with recurrence}

Thirteen patients $(48.1 \%)$ had recurrence of GAVE at a mean time of 18.2 months (range $4.7-51.8$ ). The only predictor of recurrence was greater number of pre-procedure blood transfusions ( $>$ Table 4 ). 
- Table 3 Features associated with endoscopic clinical response.

\begin{tabular}{|c|c|c|c|c|c|c|}
\hline & \multicolumn{3}{|c|}{ Univariate Analysis } & \multicolumn{3}{|c|}{ Multivariate Analysis } \\
\hline & OR & $95 \% \mathrm{Cl}$ & $P$ value & OR & $95 \% \mathrm{Cl}$ & $P$ value \\
\hline Age & 0.98 & $0.92-1.06$ & 0.65 & & & \\
\hline Sex & 0.29 & $0.05-1.80$ & 0.18 & & & \\
\hline Cirrhosis & 0.40 & $0.04-3.96$ & 0.43 & & & \\
\hline CRF & 11.88 & $1.19-118.50$ & 0.04 & 5.65 & $0.41-77.55$ & 0.20 \\
\hline GAVE type & 0.63 & $0.10-4.01$ & 0.62 & & & \\
\hline Active bleeding & 0.73 & $0.11-4.69$ & 0.74 & & & \\
\hline APC pre & 1.46 & $0.25-8.58$ & 0.68 & & & \\
\hline Transfusion pre & 0.95 & $0.28-3.20$ & 0.93 & & & \\
\hline Hb baseline & 1.09 & $1.01-1.19$ & 0.03 & 1.08 & $0.99-1.18$ & 0.099 \\
\hline Iron baseline & 1.04 & $0.94-1.17$ & 0.44 & & & \\
\hline Ferritin baseline & 0.995 & $0.99-1.001$ & 0.099 & 1.00 & $0.99-1.01$ & 0.94 \\
\hline
\end{tabular}

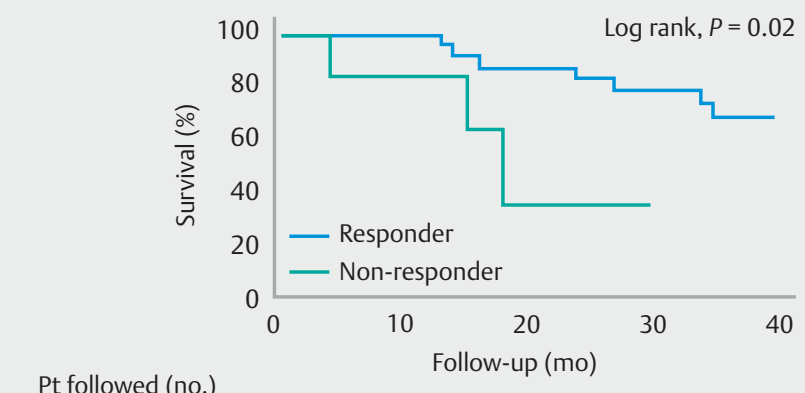

\begin{tabular}{cccccc}
27 & 25 & 18 & 14 & 10 \\
\hline & 6 & 4 & 1 & 0 &
\end{tabular}

- Fig. 2 Kaplan-Meier survival graph for responders versus nonresponders to $\mathrm{EBL}$ of GAVE at long-term follow-up.

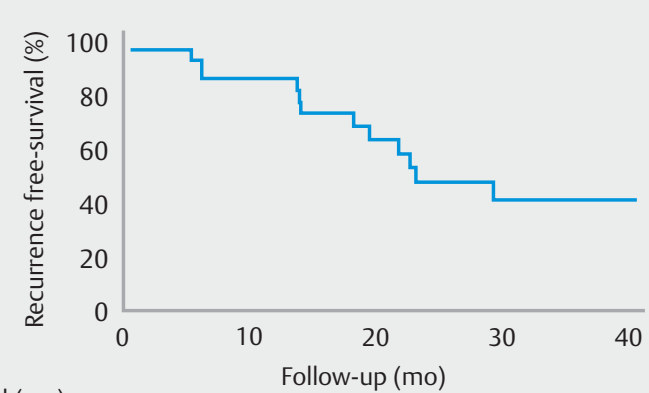

Pt followed (no.)

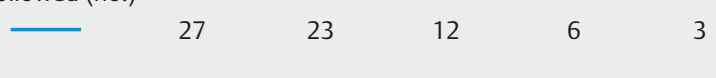

- Fig.3 Graph demonstrating recurrence-free survival at longterm follow-up for responders to EBL.
- Table4 Features associated with recurrence by Cox Regression Analysis.

\begin{tabular}{|l|l|l|l|}
\hline \multicolumn{4}{|l|}{ Univariate analysis } \\
\hline & HR & $95 \%$ Cl & $\boldsymbol{P}$ value \\
\hline Age & 0.97 & $0.93-1.03$ & 0.29 \\
\hline Sex & 0.27 & $0.00-14.07$ & 0.27 \\
\hline Cirrhosis & 1.19 & $0.32-4.35$ & 0.79 \\
\hline CRF & 1.49 & $0.41-5.45$ & 0.54 \\
\hline GAVE type & 1.25 & $0.40-3.84$ & 0.70 \\
\hline Active bleeding & 0.77 & $0.28-2.31$ & 0.64 \\
\hline APC pre & 0.40 & $0.13-1.12$ & 0.11 \\
\hline Transfusion pre & 1.79 & $0.97-3.92$ & 0.06 \\
\hline Sessions & 1.06 & $0.86-1.31$ & 0.56 \\
\hline Bands & 1.01 & $0.94-1.08$ & 0.79 \\
\hline Hb baseline & 1.01 & $0.98-1.05$ & 0.47 \\
\hline Iron baseline & 0.97 & $0.92-1.02$ & 0.21 \\
\hline Ferritin baseline & 0.99 & $0.98-101$ & 0.41 \\
\hline $\begin{array}{l}\text { HRs and } P \text { values were estimated using Cox regression analysis. } \\
\text { CRF, chronic renal failure; GAVE, gastric antral vascular ectasia; APC, argon } \\
\text { plasma coagulation; Hb, hemoblobin. }\end{array}$ & & \\
\hline
\end{tabular}

\section{Discussion}

This study evaluated long-term outcomes of endoscopic band ligation (EBL) in treatment of GAVE.

Histopathological changes that occur in esophageal varices following rubber band ligation have been described before in 
the literature, with vascular thrombosis leading to ischemic necrosis, superficial ulceration, and eventually submucosal fibrosis. [12]. It could be postulated that this mechanism also applies elsewhere in the gastrointestinal tract, including in treatment of GAVE. Argon plasma coagulation and associated thermal treatment modalities, by comparison, may fail to provide sufficient penetration to these vessels within the submucosa, or to cover a significant enough field for successful eradication.

EBL achieved a clinical response in 27 patients (81.8\%) after a mean of three procedures. A higher starting hemoglobin level was predictive of resolution of GAVE. Baseline hemoglobin level may possibly be a reflector of severity of GAVE in patients and likelihood of response to EBL. Clinically, this could suggest that earlier referral and treatment of GAVE with EBL may improve patient outcome and reduce probability of recurrence. Patients who responded to EBL had longer overall length of survival. Mortality in patients without good initial response was not directly associated with bleeding, however, this could be a factor associated with poor prognosis in patients with chronic comorbidities. Recurrence was seen in almost half the patients at 18.2 months after initial eradication. This is specific only to patients who were followed for at least the mean follow-up period time.

To our knowledge, this is the first study examining more long-term outcomes of EBL as treatment for GAVE. Our previous prospective study demonstrated a $91 \%$ clinical response over a mean follow-up of 10 months [9]. In our current study, the long-term recurrence rate of GAVE and associated bleeding after EBL was $48.1 \%$ at a mean follow-up of 18.2 months (range $4.7-51.8)$.

A review of previous published studies of APC for treatment of GAVE shows an initial good response, however, recurrent bleeding rates range from $35 \%$ to $78.9 \%$ [4].

Only two studies have evaluated recurrence of bleeding at long-term follow-up after APC treatment for GAVE. One included 62 patients, however, only 16 (25\%) did not have recurrence of bleeding at $46.9 \pm 26.5$ months [5]. Another retrospective study that included 18 patients showed a recurrence/rebleeding rate of $39 \%$ after a mean follow-up of 42 months [6]. Our study shows the importance of close follow-up of patients with GAVE even after initial clinical response as almost $50 \%$ of them will have recurrence at around 18 months. These patients can be treated again endoscopically with EBL and in some cases, APC may be utilized as a complementary treatment. This may be particularly useful in situations where there are areas with scar tissue from previous banding that are difficult to suction and achieve banding. In theory, factors that could favor recurrence of GAVE may include comorbidities such as chronic renal failure, which promotes neovascularization from chronic ischemia; this was observed in our prospective study where the two patients without initial response had this condition. A larger cohort of patients would be necessary to confirm or rule out this hypothesis. Close follow-up of patients with GAVE would allow a prompter endoscopic therapy when initial features of endoscopic recurrence are identified before patients develop further anemia or overt gastrointestinal bleeding. Furthermore, patients found to be refractory to endoscopic therapy could be considered for other treatments such as radiofrequency ablation or surgical antrectomy.

We accept that this is a small, retrospective study that has not been designed to directly compare EBL with thermal therapies such as APC in treatment of GAVE. More studies with a larger number of patients should follow to achieve a deeper understanding of this condition and its management.

\section{Conclusion}

In summary, this is the first study to evaluate long-term response and recurrence in patients with GAVE after treatment with EBL and predictors of clinical response after initial endoscopic therapy have been identified.

\section{Competing interests}

None

\section{References}

[1] Fuccio L, Mussetto A, Laterza L et al. Diagnosis and management of gastric antral vascular ectasia. Gut 1995; 37: 488-492

[2] Ito M, Uchida Y, Kamano $S$ et al. Clinical comparison between two subsets of gastric antral vascular ectasia. Gastrointest Endosc 2001; 53: $764-770$

[3] Suit PF, Petras RE, Bauer TW et al. Gastric antral vascular ectasia. A histologic and morphometric study of watermelon stomach. Am J Pathol 1987; 11: $750-757$

[4] Zepeda-Gómez S. Endoscopic treatment for gastric antral vascular ectasia: Current options. GE Port J Gastroenterol 2017; 24: 176-182

[5] Boltin D, Gingold-Belfer R, Lichtenstein L et al. Long-term treatment outcome of patients with gastric antral vascular ectasia treated with argon plasma coagulation. Eur J Gastroenterol Hepatol 2014; 26: $588-593$

[6] Baudet JS, Diaz-Bethencourt D, Soler M et al. Long-term follow-up of patients with gastric antral vascular ectasia treated with argon plasma coagulation. Med Clin (Barc) 2009; 11: $217-220$

[7] Nakamura S, Mitsunaga A, Konishi $\mathrm{H}$ et al. Long-term follow up of gastric antral vascular ectasia treated by argon plasma coagulation. Dig Endosc 2006; 18: 128-133

[8] Sinha SK, Udawat HP, Varma S et al. Watermelon stomach treated with endoscopic band ligation. Gastrointest Endosc 2013; 5: 135 137

[9] Zepeda-Gómez S, Sultanian R, Teshima C et al. Gastric antral vascular ectasia: a prospective study of treatment with endoscopic band ligation. Endoscopy 2015; 47: $538-540$

[10] Wells CD, Harrison ME, Gurudu SR et al. Treatment of gastric antral vascular ectasia (watermelon stomach) with endoscopic band ligation. Gastrointest Endosc 2008; 68: 231-236

[11] Elhendaway M, Mosaad S, Alkhalawany W et al. Randomized controlled study of endoscopic band ligation and argon plasma coagulation in the treatment of gastric antral and fundal vascular ectasia. United European Gastroenterol J 2016; 4: 423-428

[12] Polski JM, Brunt EM, Saeed ZA. Chronology of histological changes after band ligation of esophageal varices in humans. Endoscopy 2001; 33: $443-447$ 